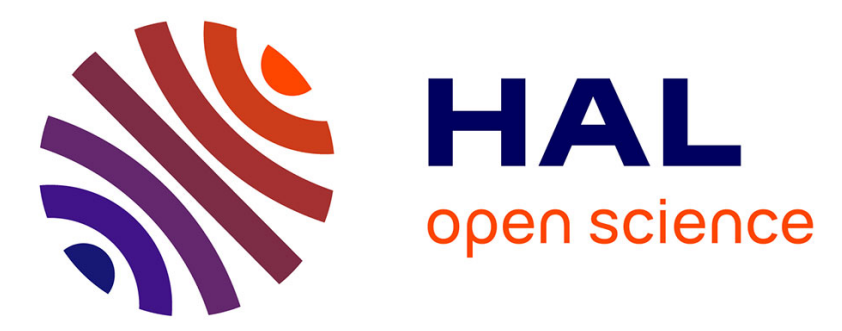

\title{
Constraints associated with captivity alter craniomandibular integration in wild boar
}

\author{
Dimitri Neaux, Barbara Blanc, Katia Ortiz, Yann Locatelli, Renate \\ Schafberg, Anthony Herrel, Vincent Debat, Thomas Cucchi
}

\section{To cite this version:}

Dimitri Neaux, Barbara Blanc, Katia Ortiz, Yann Locatelli, Renate Schafberg, et al.. Constraints associated with captivity alter craniomandibular integration in wild boar. Journal of Anatomy, 2021, 10.1111/joa.13425 . hal-03178859

\section{HAL Id: hal-03178859 \\ https://hal.sorbonne-universite.fr/hal-03178859}

Submitted on 24 Mar 2021

HAL is a multi-disciplinary open access archive for the deposit and dissemination of scientific research documents, whether they are published or not. The documents may come from teaching and research institutions in France or abroad, or from public or private research centers.
L'archive ouverte pluridisciplinaire HAL, est destinée au dépôt et à la diffusion de documents scientifiques de niveau recherche, publiés ou non, émanant des établissements d'enseignement et de recherche français ou étrangers, des laboratoires publics ou privés. 
1 Constraints associated with captivity alter craniomandibular integration in wild boar

2

3 Dimitri Neaux ${ }^{1,2^{*}}$, Barbara Blanc ${ }^{3}$, Katia Ortiz ${ }^{3,4}$, Yann Locatelli ${ }^{3,5}$, Renate Schafberg ${ }^{6}$, 4 Anthony Herrel $^{7}$, Vincent Debat ${ }^{4}$, Thomas Cucchi ${ }^{1 *}$

$6{ }^{1}$ Archéozoologie, Archéobotanique: Sociétés, Pratiques et Environnements, UMR 7209,

7 Muséum national d'Histoire naturelle CNRS, Paris, France

$8{ }^{2}$ Laboratoire Paléontologie Evolution Paléoécosystèmes Paléoprimatologie, UMR 7262,

9 Université de Poitiers CNRS, Poitiers, France

$10{ }^{3}$ Réserve Zoologique de la Haute Touche, Muséum national d'Histoire naturelle, Obterre,

11 France

$12{ }^{4}$ Institut de Systématique, Evolution, Biodiversité, UMR 7205, Muséum national d'Histoire 13 naturelle CNRS UPMC EPHE, Paris, France

$14{ }^{5}$ Physiologie de la Reproduction et des Comportements, UMR 7247, INRAE CNRS Université 15 de Tours IFCE, Nouzilly, France

$16{ }^{6}$ Central Natural Science Collections, Martin-Luther-University Halle-Wittenberg, Halle

17 (Saale), Germany

$18{ }^{7}$ Mécanismes Adaptatifs et Evolution, UMR 7179, Muséum national d'Histoire naturelle 19 CNRS, Paris, France

21 Running page heading: Captivity alters craniomandibular integration 


\section{Abstract}

24 The domestication process is associated with substantial phenotypic changes through time. 25 However, although morphological integration between biological structures is purported to 26 have a major influence on the evolution of new morphologies, little attention has been paid to

27 the influence of domestication on the magnitude of integration. Here, we assessed the influence 28 of constraints associated with captivity, considered as one of the crucial first steps in the domestication process, on the integration of cranial and mandibular structures. We investigated the craniomandibular integration in Western European Sus scrofa, using three-dimensional (3D) landmark-based geometric morphometrics. Our results suggest that captivity is associated with a lower level of integration between the cranium and the mandible. Plastic responses to captivity can thus affect the magnitude of integration of key functional structures. These findings underline the critical need to develop integration studies in the context of animal domestication to better understand the processes accountable for the setup of domestic phenotypes through time.

Keywords: domestication, morphological integration, modularity, geometric morphometrics, cranium, skull 


\section{Introduction}

Domestication is the ongoing process of the intensification of interactions between humans and other animals (Vigne, 2011; Zeder, 2012) associated with substantial phenotypic changes through time (Zeder, 2015; Sánchez-Villagra et al., 2016; Lord et al., 2020). Identifying the mechanisms responsible for the emergence of domestication is crucial to understand its role in the trajectories of human societies over the last 10,000 years (Zeder, 2018) and the emergence of humans as a new evolutionary selective force (Erlandson \& Braje, 2013; Smith \& Zeder, 2013). The initial morphological changes associated with the first responsive steps of animal populations to anthropogenic environments, prior to the emergence of selected breeds, are largely unknown and remain unidentified. Controlling the behaviour of wild animals, where they are removed from their natural habitat and moved into an anthropogenic environment, is generally considered as a first step and a catalyst of the domestication process (Vigne, 2015; Zeder, 2015). Previous studies have shown that a lifetime in captivity can induce changes in the functional demands of wild animals (e.g. locomotor, foraging, or feeding behaviours), modifying the shape of craniomandibular (Hartstone-Rose et al., 2014; Selvey, 2018; Neaux et al., 2020) and postcranial bony structures (Morimoto et al., 2011; Panagiotopoulou et al., 2019; Harbers et al., 2020) and that captivity can leave an anatomical print on the musculoskeletal system, beyond the phenotypic variation range observed in animals in their natural habitat.

For a comprehensive understanding of these processes, it is crucial to take into account that morphological structures, such as the cranium and the mandible, may respond to constraints in a coordinated fashion as they are morphologically integrated (Olson \& Miller, 1958; Cheverud, 1982; Klingenberg, 2008). This coinheritance of character complexes (Cheverud, 1995) has been described as the consequence of shared genetic processes, developmental pathways, functional selective pressures, and/or phylogenetic constraints (Marcucio et al., 2011; Parsons 
et al., 2015; Martínez-Abadías et al., 2016). Morphological integration, defined as the tendency of different traits to vary jointly in a coordinated manner (Klingenberg, 2008), has been suggested as having a major influence on morphological evolution (Wagner \& Altenberg, 1996; Schlosser \& Wagner, 2004; Klingenberg, 2005). Indeed, a high degree of covariation between structures (i.e. strong level of integration) channels morphological variation along specific trajectories of shape space, reducing the range of potential phenotypic diversity by constraining evolution along "lines of evolutionary least resistance" (Fig. 1.a; Schluter, 1996; Marroig et al., 2004; Wagner et al., 2007; Goswami \& Polly, 2014). Conversely, a low covariation reduces the constraints on morphological variation. In this case, the evolution of traits is equally possible in all directions of the shape space as the different structures can respond independently to selective forces, increasing the extent of potential phenotypic diversity. A link between environmental factors, acting during the life of an individual, and modifications in the magnitude of integration has been suggested (Cheverud, 1995; Klingenberg, 2014). It has been hypothesized that morphological integration is labile in response to changes in environmental conditions and that the correlations between phenotypic traits can be altered by the environment (Pigliucci \& Schlichting, 1998). Indeed, as integration results from the coordinated plastic responses of several traits to variation in environmental factors, it is likely that changes in these factors may cause variation in the magnitude of integration. In this sense, the need for studies disentangling the relationship between morphological changes, due to environmental factors, and the level of integration has already been underlined (Klingenberg, 2014).

To assess the impact of a lifetime of growth in a captive artificial environment on morphological integration in an ungulate, we used an experimental approach focusing on the skull of wild boar. We collected weaned wild boar piglets from a genetically homogenous population and raised them in a captive anthropogenic environment close to their initial habitat (100 km away). In 
this experimental farm, the piglets were separated into two groups where their natural foraging behaviour was suppressed $\left(100 \mathrm{~m}^{2}\right.$ stall with no possibility of foraging) or drastically limited (3,000 $\mathrm{m}^{2}$ pen with limited possibility of foraging due to the lack of space); they were fed primarily on processed dry food pellets, developed for pig farming. We compared the level of morphological integration in the captive wild boar specimens with wild-caught wild boar populations. The captive wild boar had little possibility to forage and were fed on a diet requiring little mechanical demands. We hypothesized that the constraints of captivity during their growth, by reducing the range of functions performed and relaxing the need for functional integration, may be linked to a significant reduction in the magnitude of integration.
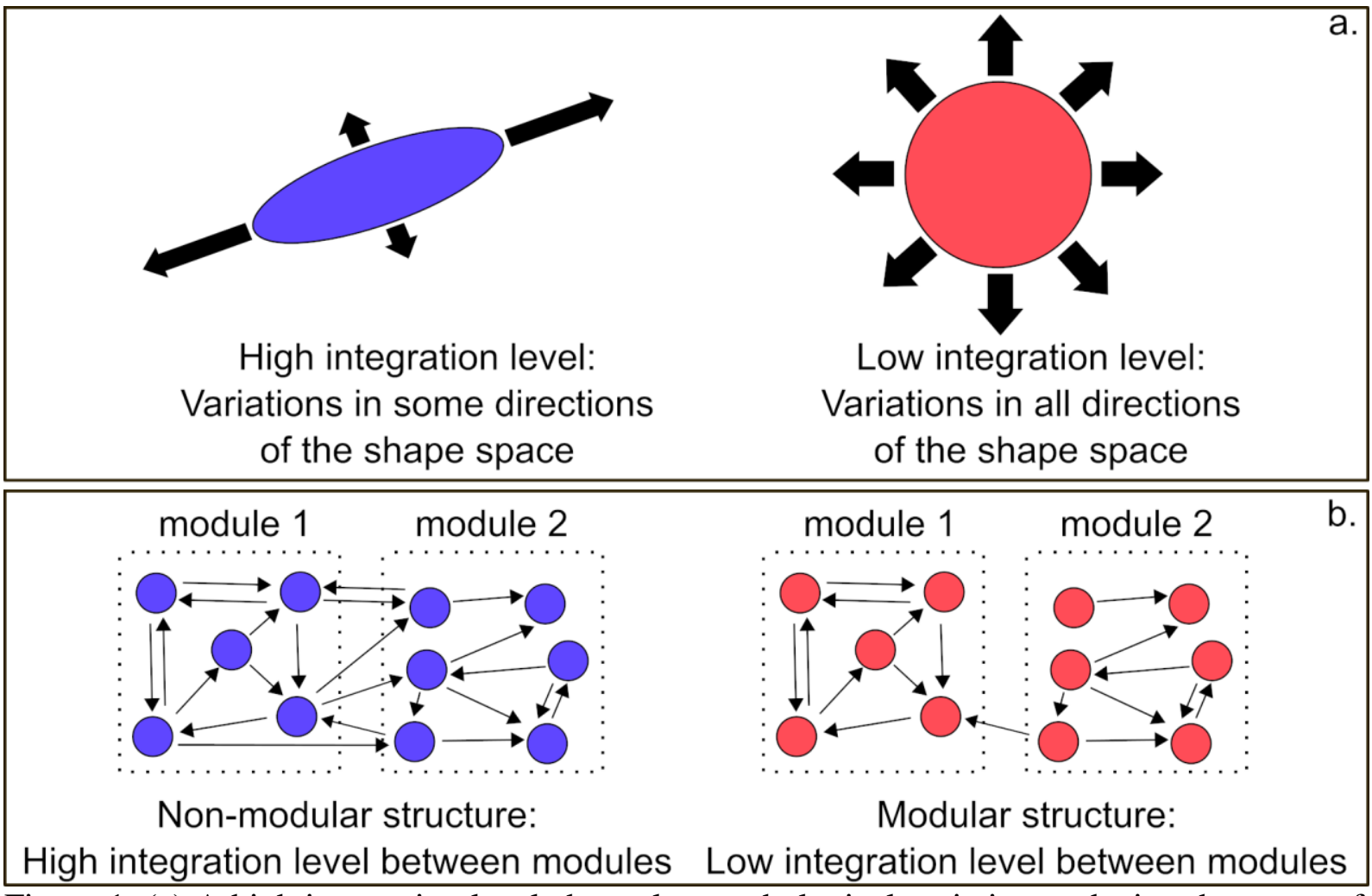

Figure 1. (a) A high integration level channels morphological variation, reducing the range of potential phenotypic diversity. A low integration level minimises constraints on morphological variation, increasing the extent of potential phenotypic diversity. (b) Modularity exists if integration is concentrated within certain parts of a structure (the modules) but is relatively weak between these modules. Modularity therefore means that integration in a structure is 
compartmentalised, with strong integration within modules and weak integration between modules. Modified after Klingenberg $(2008,2010)$.

\section{Material and methods}

\section{Material}

The dataset was composed of 46 adult European wild boar and pig skulls belonging to four different groups (see Supporting Information Data S1). We chose specimens from a limited region (i.e. Western Europe) to reduce the confounding effects of geographic and climateinduced morphological variation known to exist in Sus scrofa (Albarella et al., 2009). The first two groups consisted of wild boar from the DOMEXP project: a multidisciplinary experiment aiming to assess the effect of captivity on the musculoskeletal system (http://anrdomexp.cnrs.fr/). To test the plastic response of mobility reduction on the shape of a wild ungulate skull, we relied on a control population of wild boar living in a $100,000 \mathrm{~m}^{2}$ fenced forest in Urciers (France). From this population, we sampled 24 piglets that were divided into two groups of 12 specimens of equal sex ratio ( 6 males and 6 females). These groups were raised from 6 to 24 months at the Zoological Reserve of La Haute Touche (France) in two different contexts of mobility reduction: an indoor stall of $100 \mathrm{~m}^{2}$ ('stall - captive' group) offering no possibility of natural foraging, and a 3,000 $\mathrm{m}^{2}$ wooded pen ('enclosure - captive' group) with only limited natural foraging possible. We supplied both groups with the same processed dry food pellets, including $15.5 \%$ of raw protein adapted for pig diets. This experiment received ethics approval from the French Ministère de l'Enseignement Supérieur et de la Recherche (APAFIS\#5353-201605111133847). The relatively small sample sizes for the 'stall - captive' and the 'enclosure - captive' groups are inherent to the experimental nature of the study. As sample size can affect the results of integration studies (Rohlf \& Corti, 2000; Bookstein et al., 2003), we choose to use similar sample sizes for the other studied groups. In 
addition to the two captive groups, we also sampled adult free-ranging specimens ('wildcaught' group). This group included four individuals from the initial free-ranging herd of Urciers, (i.e. the same population as the captive ones). These specimens came from a wild boar farm, where human interactions are intentionally kept to a minimum in order to ensure that the behaviour of the wild boar remains as natural as possible. They are free to forage for food in the woods. In addition to the specimens of the DOMEXP project, the 'wild-caught' group also included seven free-ranging wild boar from the same geographic and climatic environment (i.e. temperate central France) as the DOMEXP specimens. Like most wild boar in Western Europe, these free ranging specimens had an omnivorous diet consisting mostly of vegetable foods, e.g. acorns, roots and crops (Schley \& Roper, 2003). All these specimens were wild-caught between one and two years of age. We included a fourth group of long-term domesticated populations of German, Polish, and French Landrace pigs ('Landrace' group), i.e. locally adapted traditional breeds (Negri et al., 2009). They were raised in stalls, with a strong mobility reduction, and were between one and nine years of age.

\section{Data acquisition and analyses}

We used 94 homologous landmarks and 67 semilandmarks placed on three-dimensional (3D) surfaces to describe the cranial and mandibular shape (Supporting Information Data S2). We digitised the anatomical landmarks and semilandmarks using IDAV Landmark v3.0 software (Wiley et al., 2005). We performed all the analyses in the R environment (R Core Team, 2019). To remove variation related to their initial arbitrary position along the curves, the semilandmarks were slid along the tangent of the curves minimising bending energy (Gunz \& Mitteroecker, 2013). These were then superimposed with the fixed landmarks using a generalised Procrustes superimposition (Rohlf \& Slice, 1990), implemented in the gpagen function of the package 'geomorph' (Adams et al., 2019) to obtain a new set of shape variables 
(Procrustes coordinates) and the centroid size (CS). The cranial and mandibular landmarks were subject to separate Procrustes superimpositions in order to avoid the increase of covariance and spurious results (Cardini, 2018).

Allometry is known to significantly affect the level of morphological integration as sizedependent shape changes contribute to produce integration between structures (Klingenberg \& Marugán-Lobón, 2013); therefore, we performed Procrustes ANOVAs (Klingenberg \& McIntyre, 1998) with permutation procedures to quantify the allometry, with size computed as the decimal logarithm of CS (log CS; Collyer et al., 2015). This test was performed with the procD.lm function of the package 'geomorph' (Adams et al., 2019). We also tested the difference between the allometric slopes of the studied groups. Assuming that these differences were not significant, all the following analyses were computed on both the raw shape data and on size-corrected shape data, which are the residuals from the global multivariate regression of the shape against $\log$ CS, to account for the effect of allometry (Monteiro, 1999).

We performed a principal component analysis (PCA) using gm.prcomp ('geomorph') on all groups to assess the overall morphological variation and the distribution of individuals in the shape space. We evaluated the significance of shape differences among groups by performing a Procrustes ANOVA on aligned Procrustes coordinates using procD.lm.

To quantify the shape covariation, partial least squares (PLS) analyses (Rohlf \& Slice, 1990; Bookstein, 1991) and covariance ratios (CR; Adams, 2016; Adams \& Collyer, 2016) were used jointly, as recommended by Adams (2016). We quantified the covariation as a proxy for the integration of cranium and mandible for each pair of axes by a correlation coefficient rPLS using integration.test ('geomorph'). This coefficient is supported by a permutation test for the 
null hypothesis that the distribution of specimens on one axis has no bearing on the distribution of the other axis. We computed the heatmap of shape deformations along the PLS axes to assess the location and the intensity of covariations using meshDist from the 'Morpho' package (Schlager \& Jefferis, 2020). In addition, differences in integration patterns were assessed by examining the general orientation of each group's distribution on the PLS scores (Mitteroecker \& Bookstein, 2008; Singh et al., 2012; Neaux, 2017). For this purpose, we tested for differences in the regression slopes between the studied groups on the between-group PLS. We assessed the overall modularity between cranium and mandible modules using the $\mathrm{CR}$ from modularity.test ('geomorph'). Modularity exists if integration is compartmentalised, i.e. concentrated within certain parts of a structure (the modules) but relatively weak between modules (Fig 1.b; see Supporting Information Data S3). The value of CR provides a measure for characterising and evaluating the degree of modularity in biological data sets (Adams, 2016; Adams \& Collyer, 2016). Morphological integration and modularity were assessed including all groups (between-group covariation) and within groups (within-group covariation).

\section{Results}

\section{Variation analyses}

Allometry explains nearly $20 \%$ of the shape variation in the cranium $(p<0.01 ; 19.74 \%$ of the total variance) and the mandible ( $p<0.01 ; 17.39 \%$ of the total variance). The allometric slopes did not differ between the studied groups for the cranium $(p=0.44)$ or the mandible $(p=0.16)$. In addition to raw shape, we computed the size corrected shape variables for further analyses. On the PCA, PC1 accounted for $56.41 \%$ and $31.24 \%$ of the total variance for the cranium and mandible respectively (Supporting Information Data S4). For both structures, PC1 was driven by the strong divergence between the wild boar phenotype towards the negative side of the axis and the Landrace pigs towards the positive side. For the cranium, PC2 mainly separates the 
wild-caught from the captive wild boar. It is noteworthy that the plastic effect displayed on PC2

208 is different from the shape divergence between the wild boar and pigs, displayed on PC1, as the two shape changes are located on different PCs. We found significant $(p<0.05)$ pairwise differences of raw cranial shapes between all groups and the 'Landrace' but not between the 211 wild boar groups (Supporting Information Data S4). We found the same results for the 212 allometry-free cranial shapes. We found significant $(p<0.05)$ pairwise differences of 213 mandibular raw shapes between all groups except between the 'stall - captive' and 'enclosure 214 - captive' groups. For the allometry-free mandibular shapes, the difference between the 'stall - captive' and the 'wild-caught' groups was also not significant.

\section{Between-group covariation analyses}

The correlation coefficient of the first pair of PLS axes (PLS1) between the cranium and the mandible for all the studied specimens is strong and significant for raw (rPLS $=0.89 ; \mathrm{p}<0.01$; Table 1, Fig. 2.a) and allometry-free shapes (rPLS = 0.88; $\mathrm{p}<0.01$ ). The PLS1 pairs of axes account respectively for $86.65 \%$ and $92.67 \%$ of the total covariation. The main deformation associated with PLS1 is located in the anterior part of the nasal, in the nuchal crest region, in the zygomatic process of the frontal and in the tip of paroccipital processes for the cranium (Fig. 2.b). For the mandible, they are visible in the maximum of curvature between the mandibular ramus and corpus, in the inner part of the gonial angle region, on the insertion of the lower canines, and on the ventral part of the symphysis. The regression slopes between the studied groups were not different between the studied groups for the cranium $(p=0.44)$ or the mandible $(p=0.16)$ between-group PLS 1. The CR for all the studied specimens indicates a significant modularity between the cranium and mandible for raw $(\mathrm{CR}=0.81 ; p<0.01$; Table 1) and allometry-free shapes $(\mathrm{CR}=0.70 ; p<0.01)$. 


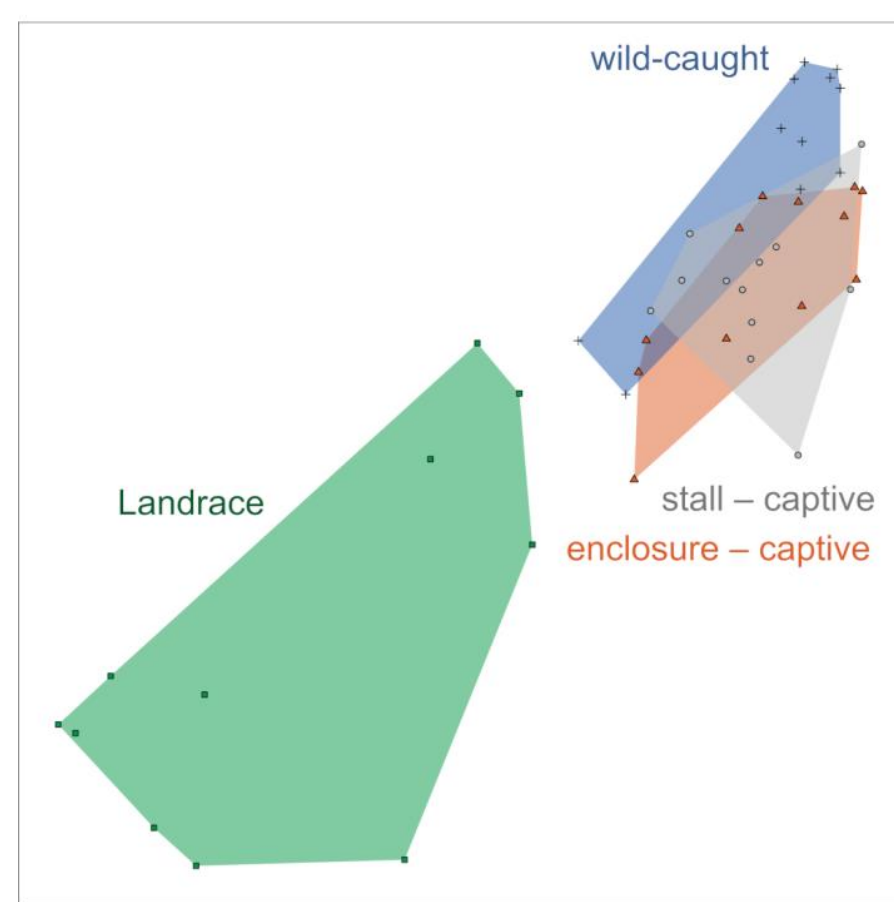

a.

234 Figure 2. (a) First pair of partial least squares analysis axes (PLS1) between cranial and 235 mandibular shape for all specimens. (b) Heatmap of the intensity of shape covariation on PLS 2361 ; blue indicates a low intensity of covariation and red indicates a high intensity of covariation.

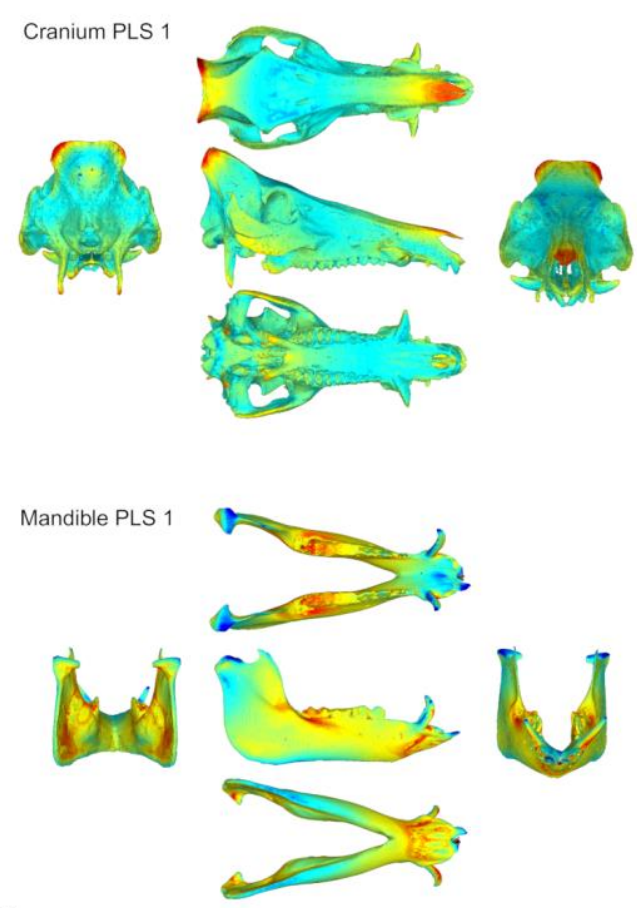

b. 
238 Table 1. Values of PLS, covariance ratios and coefficients for raw shapes and allometry-free 239 shapes. rPLS: PLS coefficient of the first pair of PLS axes, \%EC: percentage of covariation 240 explained by the first pair of PLS axes, CR: Covariance Ratio.

\begin{tabular}{lccccc}
\hline & rPLS & $p$-value & \%EC & CR & $p$-value \\
\hline raw shapes & & & & & \\
all groups & $\mathbf{0 . 8 9}$ & $<\mathbf{0 . 0 1}$ & $\mathbf{8 5 . 6 5}$ & $\mathbf{0 . 8 1}$ & $<\mathbf{0 . 0 1}$ \\
stall - captive & 0.82 & 0.51 & 59.33 & $\mathbf{0 . 7 1}$ & $<\mathbf{0 . 0 1}$ \\
enclosure - captive & $\mathbf{0 . 8 9}$ & $\mathbf{0 . 0 4}$ & $\mathbf{7 6 . 7 4}$ & $\mathbf{0 . 8 4}$ & $<\mathbf{0 . 0 1}$ \\
wild-caught & $\mathbf{0 . 9 7}$ & $<\mathbf{0 . 0 1}$ & $\mathbf{7 2 . 8 6}$ & $\mathbf{0 . 9 5}$ & $<\mathbf{0 . 0 1}$ \\
Landrace & 0.88 & 0.06 & 69.31 & $\mathbf{0 . 8 1}$ & $<\mathbf{0 . 0 1}$ \\
\hline allometry free-shapes & & & & & $<$ \\
all groups & $\mathbf{0 . 8 8}$ & $<\mathbf{0 . 0 1}$ & $\mathbf{9 2 . 6 7}$ & $\mathbf{0 . 7 0}$ & $<\mathbf{0 . 0 1}$ \\
stall - captive & 0.89 & 0.29 & 56.90 & $\mathbf{0 . 8 8}$ & $<\mathbf{0 . 0 1}$ \\
enclosure- captive & $\mathbf{0 . 8 8}$ & $\mathbf{0 . 0 4}$ & $\mathbf{7 6 . 9 0}$ & $\mathbf{0 . 8 4}$ & $<\mathbf{0 . 0 1}$ \\
wild-caught & $\mathbf{0 . 9 7}$ & $<\mathbf{0 . 0 1}$ & $\mathbf{5 6 . 1 4}$ & $\mathbf{0 . 9 7}$ & $<\mathbf{0 . 0 1}$ \\
Landrace & 0.84 & 0.52 & 32.16 & $\mathbf{0 . 8 8}$ & $<\mathbf{0 . 0 1}$ \\
& & & & &
\end{tabular}

241 Significant values $(p<0.05)$ are in bold.

243 Within-group covariation analyses

244 The PLS computed for each studied group showed a significant level of integration for the 245 'enclosure - captive' and 'wild-caught' groups for raw shapes (rPLS = 0.89; $p=0.04$; Table 1) 246 and (rPLS $=0.97 ; \mathrm{p}<0.01)$, and allometry-free shapes $(\mathrm{rPLS}=0.88 ; \mathrm{p}=0.04)$ and $(\mathrm{rPLS}=$ 247 0.97; $\mathrm{p}<0.01)$. The correlation coefficients of PLS1 are not significant for the 'stall - captive' 248 and 'Landrace' groups. The main deformation associated with PLS1 includes important 249 changes in the anterior extremity of the rostrum, the occipital region, the lateral side of the 
ramus and the symphysis region for both the 'enclosure - captive' (Fig. 3.a) and 'wild-caught'

251 (Fig. 3.b) groups. Deformations include changes in the ventral edge of the zygomatic arch and

252 in the pterygoid fossa region for the 'wild-caught' group. The CR values for all the studied 253 groups indicates a significant modularity between the cranium and the mandible (Table 1).

Cranium PLS 1

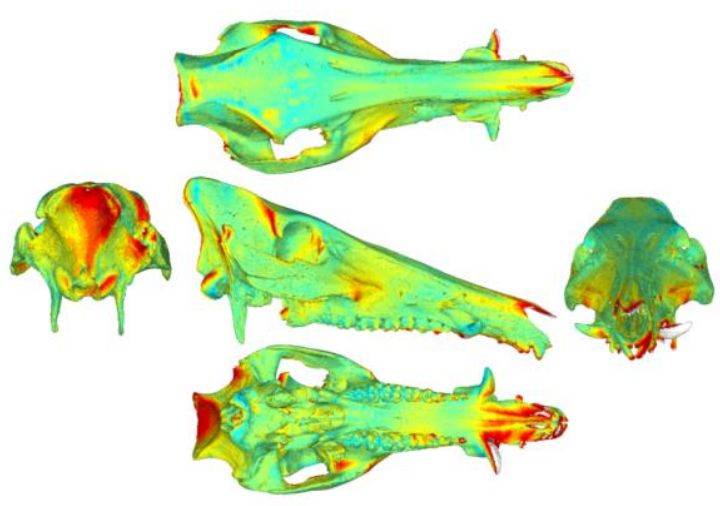

Mandible PLS 1
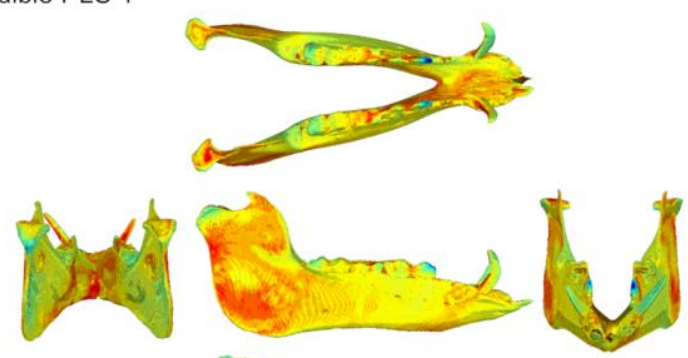

a.

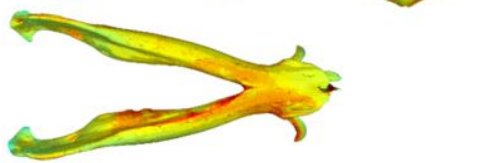

Cranium PLS 1
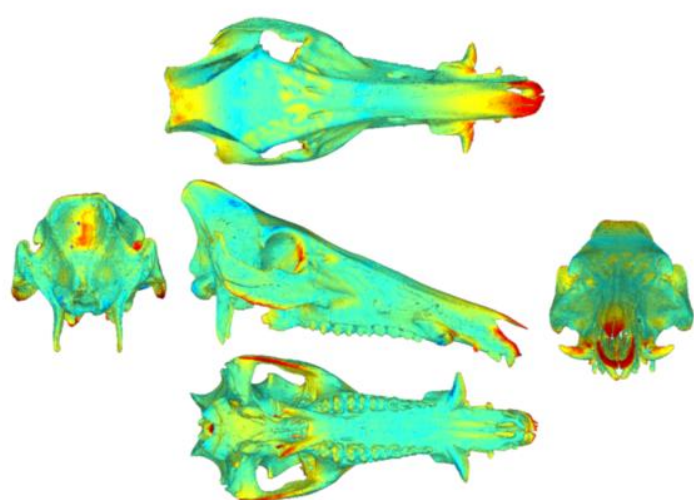

Mandible PLS 1

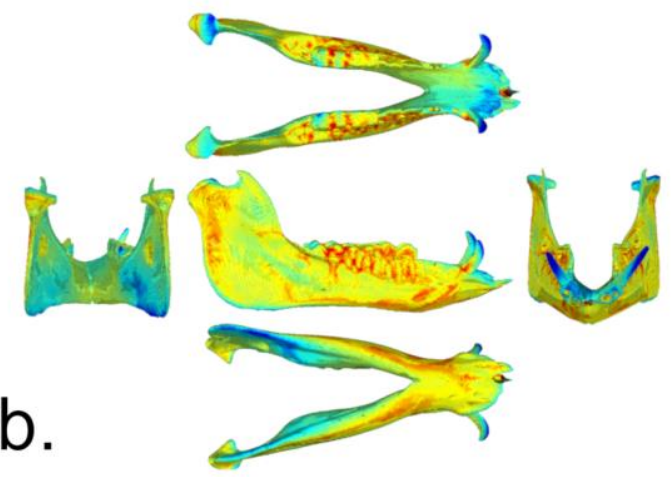

Figure 3. Heatmap of the shape covariation intensity of partial least squares analysis axes (PLS 1) for (a) the enclosure - captive' group and (b) the 'wild-caught' group. Blue indicates a low intensity of covariation and red indicates a high intensity of covariation.

\section{Discussion}

Our analyses confirm that captivity imposed on wild boar during their growth is linked to a reduction in the magnitude of integration. The results obtained from allometry-free shape data reveal similar tendencies, indicating a relatively low impact of allometry on patterns of 
264

285 Our analyses also showed that, as for the group of captive wild boar raised in a stall, integration

covariation. This result underlines that changes in environmental factors can affect the magnitude of integration. Previous results on the same experimental sample (DOMEXP project) found that the shape of cranium and mandible are affected by changes in the functional demands associated with captivity (Neaux et al., 2020). Indeed, modifications in foraging and feeding behaviours have been identified as potential factors able to modify skull shape. Furthermore, morphological integration between the cranium and the mandible is considered as a classic example of functional integration, where two structures interact in the same functional context (Klingenberg, 2014). Indeed, the upper and lower jaws need to be coordinated to achieve proper occlusion and perform functions, such as biting and chewing (Hautier et al., 2012; Figueirido et al., 2013). Therefore, our results show that captivity, inducing changes in foraging and feeding behaviour which likely reduce the need for functional integration (Neaux et al., 2020), also diminishes the magnitude of integration between the cranium and the mandible, i.e. the structures performing these functions. In this sense, several studies have empirically shown that morphological integration can be highly variable over short timescales in response to environmental changes acting on shared developmental and functional processes (Beldade et al., 2002; Young \& Hallgrímsson, 2005; Monteiro \& Nogueira, 2010). In our study, most of the wild-caught and captive wild boar groups did not display significant differences in terms of shape disparity. This similarity underlines that though captivity modifies functional demands in wild animals (Neaux et al., 2020; Hartstone-Rose et al., 2014; Harbers et al., 2020), it does not affect their potential range of morphological variation.

\footnotetext{
is also not significant for the group composed of Landrace pigs. These traditional breeds of pigs
} share several features with the captive wild boar from our experiment. They were given daily rations, mainly composed of agricultural products and food waste, allowing the relaxation of 
environmental constraints associated with the necessity to find and process food. This relaxation in one of the main functions performed together by the cranium and mandible (i.e. mastication), may result in a weaker morphological integration between these structures in Landrace pigs, as well as in captive wild boar raised in a stall. Furthermore, these two groups share the impossibility to perform foraging and rooting as they were both raised in stalls, i.e. on artificial solid grounds. When possible, foraging and rooting are activities that both wild boar (Blasetti et al., 1988) and pigs (Buckner et al., 1998) spend a lot of time doing. Modifications in rooting frequency, impacting the development of the muscles in the neck regions, may be associated with changes in cranial shape (Owen et al., 2014). Therefore, the impossibility for both captive wild boar raised in a stall and Landrace pigs to perform such functions may also explain the non-significant integration between the cranium and the mandible observed in these two groups. This confirms that a reduction in the range of functions available is linked to a significant reduction in the magnitude of integration. Although we found differences in the integration level between the studied groups, we did not find differences in integration patterns, suggesting that changes in constraints due to captivity affect the level of covariation between structures but not the way they covary. This result was expected, as previous studies have shown that integration patterns are fairly conservative, even at high taxonomic levels (Goswami, 2006; Porto et al., 2009; Neaux et al., 2018).

For both the between-group and within-group analyses, we also found significant modularity between the cranium and the mandible, corroborating the presence of two basic independent phenotypic modules in the skull (one cranial and one mandibular). The modularity between the cranium and mandible is likely explained by their respective functional roles. Indeed, whereas the morphology of the mandible is closely related to feeding behaviour (Taylor, 2006; Daegling \& McGraw, 2007; Anderson et al., 2014), the shape of the cranium is also affected by a 
multiplicity of other functions unrelated to food consumption (e.g. vision, respiration, mastication, brain protection; Lieberman, 2011). Our results confirm that even if the cranium and the mandible can be considered as two distinct modules (i.e. integration is stronger within these structures than between them), there is still a significant relationship between them, at least in our between-group analysis, which can be defined as intermodule integration 319 (Klingenberg, 2013).

\section{Conclusion}

Our results support the hypothesis that behavioural changes associated with captivity, considered a catalyst of the animal domestication process (Vigne, 2015; Zeder, 2015), do result in a reduction of the integration between the cranium and the mandible. However, this work will need to be expanded further using a greater dataset, as the relatively small sample size, inherent to the experimental nature of our study, could have partly biased these results (Thiese be the morphological response to anthropogenic changes in the functional demands associated with captivity, constituting possible future new markers for the domestication process that could be explored in the archaeological record.

\section{Data Availability}

The data that support the findings of this study are available from the corresponding authors 334 upon reasonable request.

\section{Acknowledgements}

337 We are most grateful to the staff of the Réserve Zoologique de la Haute-Touche (Christophe 338 Audureau, Jérémy Bernard, Christophe Jubert, Sandrine Laloux, Emmanuel Maréchal, Régis 
Rabier, Patrick Roux and Colin Vion) for their help during the setup of the experimental

340 structures, the care they provided to the experimental specimens and during the data acquisition.

341 We thank the CIRE platform at INRAE (Hans Adriensen, Frédéric Elbout, Christian Moussu

342 and Luc Perrigouard), CT teams from the Leibniz-IZW in Berlin (Guido Fritsch and Juliane

343 Kühne) and the University Hospital Halle/Saale (Silvio Brandt). We would like to thank Jill

344 Cucchi for copy editing this manuscript. We are grateful to two anonymous reviewers for their

345 valuable comments and advices on an earlier version of the manuscript. This research was

346 funded by ANR, through the DOMEXP project (ANR-13-JSH3-0003-01), the LabEx ANR-10-

347 LABX-0003-BCDiv, in the programme 'Investissements d'avenir' ANR-11-IDEX-0004-02,

348 programme Emergence SU-19-3-EMRG-02, Muséum national d'Histoire naturelle (Paris), and

349 the CNRS INEE institute. We have no conflict of interest to declare.

\section{$351 \quad$ Author Contributions}

352 DN, AH, VD and TC designed the research. BB, KO, YL and TC conducted the experimental 353 fieldwork. RS and TC collected the CT data. DN carried out the GMM analyses and interpreted 354 the data with TC and VD. DN led the manuscript with scientific and editorial input from RS, 355 AH, VD and TC. All authors gave final approval for publication. 
Adams DC (2016) Evaluating modularity in morphometric data: challenges with the RV coefficient and a new test measure. Methods Ecol Evol 7, 565-572.

Adams DC, Collyer M, Kaliontzopoulou A (2019) geomorph: geometric morphometric analyses of $2 \mathrm{D} / 3 \mathrm{D}$ landmark data.

Adams DC, Collyer ML (2016) On the comparison of the strength of morphological integration across morphometric datasets. Evolution 70, 2623-2631.

Albarella U, Dobney K, Rowley-Conwy P (2009) Size and shape of the Eurasian wild boar (Sus scrofa), with a view to the reconstruction of its Holocene history. Environmental Archaeology 14, 103-136.

Anderson PS, Renaud S, Rayfield EJ (2014) Adaptive plasticity in the mouse mandible. BMC Evolutionary Biology 14, 85.

Beldade P, Koops K, Brakefield PM (2002) Developmental constraints versus flexibility in morphological evolution. Nature 416, 844-847.

Blasetti A, Boitani L, Riviello MC, et al. (1988) Activity budgets and use of enclosed space by wild boars (Sus scrofa) in captivity. Zoo Biology 7, 69-79.

Bookstein FL (1991) Morphometric Tools for Landmark Data: Geometry and Biology, Cambridge. UK: Cambridge University Press.

Bookstein FL, Gunz P, Mitteroecker P, et al. (2003) Cranial integration in Homo: singular warps analysis of the midsagittal plane in ontogeny and evolution. J Hum Evol 44, $167-187$.

Buckner LJ, Edwards SA, Bruce JM (1998) Behaviour and shelter use by outdoor sows. Applied Animal Behaviour Science 57, 69-80.

Cardini A (2018) Integration and Modularity in Procrustes Shape Data: Is There a Risk of Spurious Results? Evol Biol .46, 90-105.

Cheverud JM (1982) Phenotypic, genetic, and environmental morphological integration in the cranium. Evolution 36, 499-516.

Cheverud JM (1995) Morphological integration in the saddle-back tamarin (Saguinus fuscicollis) cranium. The American Naturalist 145, 63-89.

Collyer ML, Sekora DJ, Adams DC (2015) A method for analysis of phenotypic change for phenotypes described by high-dimensional data. Heredity 115, 357-365.

Daegling DJ, McGraw WS (2007) Functional morphology of the mangabey mandibular corpus: Relationship to dental specializations and feeding behavior. American Journal of Physical Anthropology 134, 50-62

Erlandson JM, Braje TJ (2013) Archeology and the Anthropocene. Anthropocene 4, 1-7.

Figueirido B, Tseng ZJ, Martín-Serra A (2013) Skull shape evolution in durophagous carnivorans. Evolution 67, 1975-1993. 
Goswami A (2006) Morphological integration in the carnivoran skull. Evolution 60, 169-183.

Goswami A, Polly PD (2014) The macroevolutionary consequences of phenotypic integration: from development to deep time. Philos Trans R Soc Lond, B, Biol Sci 369, 20130254.

Gunz P, Mitteroecker P (2013) Semilandmarks: a method for quantifying curves and surfaces. Hystrix, the Italian Journal of Mammalogy 24, 103-109.

Harbers H, Neaux D, Ortiz K, et al. (2020) The mark of captivity: plastic responses in the ankle bone of a wild ungulate (Sus scrofa). Royal Society Open Science 7, 192039.

Hartstone-Rose A, Selvey H, Villari JR, et al. (2014) The three-dimensional morphological effects of captivity. PLOS ONE 9, e113437.

Hautier L, Lebrun R, Cox PG (2012) Patterns of covariation in the masticatory apparatus of hystricognathous rodents: implications for evolution and diversification. Journal of Morphology 273, 1319-1337.

Klingenberg CP (2005) Developmental constraints, modules, and evolvability. In B. Hallgrímsson \& B. K. Hall, eds. Variation: A central concept in biology. Amsterdam, $1-30$.

Klingenberg CP (2008) Morphological integration and developmental modularity. Annual review of ecology, evolution, and systematics 39, 115-132.

Klingenberg CP (2010) Evolution and development of shape: integrating quantitative approaches. Nat Rev Genet 11, 623-635.

Klingenberg CP (2013) Cranial integration and modularity: insights into evolution and development from morphometric data. Hystrix, the Italian Journal of Mammalogy 24, 43-58.

Klingenberg CP (2014) Studying morphological integration and modularity at multiple levels: concepts and analysis. Phil Trans R Soc B 369, 20130249.

Klingenberg CP, Marugán-Lobón J (2013) Evolutionary covariation in geometric morphometric data: analyzing integration, modularity, and allometry in a phylogenetic context. Syst Biol 62, 591-610.

Klingenberg CP, McIntyre GS (1998) Geometric morphometrics of developmental instability: Analyzing patterns of fluctuating asymmetry with Procrustes methods. Evolution 52, 1363-1375.

Lieberman DE (2011) The Evolution of the Human Head. Cambridge: Harvard University Press.

Lord KA, Larson G, Coppinger RP, et al. (2020) The history of farm foxes undermines the animal domestication syndrome. Trends Ecol Evol (Amst) 35, 125-136.

Marcucio RS, Young NM, Hu D, et al. (2011) Mechanisms that underlie co-variation of the brain and face. Genesis 49, 177-189. 
Marroig G, De Vivo M, Cheverud JM (2004) Cranial evolution in sakis (Pithecia, Platyrrhini). II: Evolutionary processes and morphological integration. J Evol Biol 17, 144-155.

Martínez-Abadías N, Esparza M, Sjøvold T, et al. (2016) Chondrocranial growth, developmental integration and evolvability in the human skull. In J. C. Boughner \& C. Rolian, eds. Developmental approaches to human evolution. Hoboken: Wiley, 17-34.

Mitteroecker P, Bookstein F (2008) The evolutionary role of modularity and integration in the hominoid cranium. Evolution 62, 943-958.

Monteiro LR (1999) Multivariate regression models and geometric morphometrics: the search for causal factors in the analysis of shape. Syst Biol 48, 192-199.

Monteiro LR, Nogueira MR (2010) Adaptive radiations, ecological Specialization, and the evolutionary integration of complex morphological structures. Evolution 64, 724-744.

Morimoto N, Ponce de León M, Zollikofer CPE (2011) Exploring femoral diaphyseal shape variation in wild and captive chimpanzees by means of morphometric mapping: a yest of Wolff's law. The Anatomical Record 294, 589-609.

Neaux D (2017) Morphological integration of the cranium in Homo, Pan, and Hylobates and the evolution of hominoid facial structures. Am J Phys Anthropol 162, 732-746.

Neaux D, Blanc B, Ortiz K, et al. (2020) How changes in functional demands associated with captivity affect the skull shape of a wild boar (Sus scrofa). Evol Biol.

Neaux D, Sansalone G, Ledogar JA, et al. (2018) Basicranium and face : assessing the impact of morphological integration on primate evolution. Journal of Human Evolution 118, 43-55.

Negri V, Maxted N, Veteläinen M (2009) European landrace conservation: An introduction. In M. Veteläinen, V. Negri, \& N. Maxted, eds. European Landraces: On-farm Conservation, Management and Use. Rome, Italy: Biodiversity International, 1-22.

Olson EC, Miller RL (1958) Morphological Integration. Chicago, IL: University of Chicago Press.

Owen J, Dobney K, Evin A, et al. (2014) The zooarchaeological application of quantifying cranial shape differences in wild boar and domestic pigs (Sus scrofa) using 3D geometric morphometrics. Journal of Archaeological Science 43, 159-167.

Panagiotopoulou O, Pataky TC, Hutchinson JR (2019) Foot pressure distribution in White Rhinoceroses (Ceratotherium simum) during walking. PeerJ 7, e6881.

Parsons TE, Downey CM, Jirik FR, et al. (2015) Mind the gap: genetic manipulation of basicranial growth within synchondroses modulates calvarial and facial shape in mice through epigenetic interactions. PLOS ONE 10, e0118355.

Pigliucci M, Schlichting C (1998) Phenotypic Evolution: A Reaction Norm Perspective. Sunderland, MA: Sinauer Associates Inc. 
Porto A, de Oliveira FB, Shirai LT, et al. (2009) The evolution of modularity in the mammalian skull I: morphological integration patterns and magnitudes. Evol Biol 36, $118-135$.

R Core Team (2019) R: A language and environment for statistical computing, Vienna, Austria.

Rohlf FJ, Corti M (2000) Use of two-block partial least-squares to study covariation in shape. Syst Biol 49, 740-753.

Rohlf FJ, Slice D (1990) Extensions of the Procrustes method for the optimal superimposition of landmarks. Syst Biol 39, 40-59.

Sánchez-Villagra MR, Geiger M, Schneider RA (2016) The taming of the neural crest: a developmental perspective on the origins of morphological covariation in domesticated mammals. $R$ Soc Open Sci 3, 160107.

Schlager S, Jefferis G (2020) Morpho: calculations and visualisations related to geometric morphometrics.

Schley L, Roper TJ (2003) Diet of wild boar Sus scrofa in Western Europe, with particular reference to consumption of agricultural crops. Mammal Review 33, 43-56.

Schlosser G, Wagner GP (2004) Modularity in Development and Evolution. Chicago: University of Chicago Press.

Schluter D (1996) Adaptive radiation along genetic lines of least resistance. Evolution 50, 1766-1774.

Selvey H (2018) Cranial responses to captivity in Lemur catta and Propithecus verreauxi in natural history museum collections. Anthropology Graduate Theses \& Dissertations 72.

Singh N, Harvati K, Hublin J-J, et al. (2012) Morphological evolution through integration: a quantitative study of cranial integration in Homo, Pan, Gorilla and Pongo. J Hum Evol 62, 155-164.

Smith BD, Zeder MA (2013) The onset of the Anthropocene. Anthropocene 4, 8-13.

Taylor AB (2006) Feeding behavior, diet, and the functional consequences of jaw form in orangutans, with implications for the evolution of Pongo. J Hum Evol 50, 377-393.

Thiese MS, Ronna B, Ott U (2016). P value interpretations and considerations. J Thorac Dis 8, 928-931.

Vigne J-D (2011) The origins of animal domestication and husbandry: a major change in the history of humanity and the biosphere. C R Biol 334, 171-181.

Vigne J-D (2015) Early domestication and farming: what should we know or do for a better understanding? Anthropozoologica 50, 123-150. 
Wagner GP, Altenberg L (1996) Perspective: complex adaptations and the evolution of evolvability. Evolution 50, 967-976.

Wagner GP, Pavlicev M, Cheverud JM (2007) The road to modularity. Nat Rev Genet 8, 921-931.

Wiley D, Amenta N, Alcantara D, et al. (2005) Evolutionary Morphing. In Proceedings of IEEE visualization 2005. VIS'05. Minneapolis, MN: IEEE, 431-438.

Young NM, Hallgrímsson B (2005) Serial homology and the evolution of mammalian limb covariation structure. Evolution 59, 2691-2704.

Zeder MA (2012) The domestication of animals. Journal of Anthropological Research 68 , 161-190.

Zeder MA (2015) Core questions in domestication research. Proceedings of the National Academy of Sciences of the United States of America 112, 3191-3198.

Zeder MA (2018) Why evolutionary biology needs anthropology: Evaluating core assumptions of the extended evolutionary synthesis. Evol Anthropol 27, 267-284. 
516 SUPPORTING INFORMATION

\section{Data S1: Groups and specimens used}

518 a. List of groups included in the study and number of specimens

\begin{tabular}{ll}
\hline Group & Number of specimens \\
\hline stall - captive & 12 \\
enclosure - captive & 12 \\
wild-caught & 11 \\
Landrace & 11 \\
TOTAL & 46 \\
\hline
\end{tabular}

519 
b. List of specimens. M: male, F: female.

\begin{tabular}{|c|c|c|c|c|c|}
\hline Catalogue number & $\operatorname{Sex}^{1}$ & $\begin{array}{l}\text { Age } \\
\text { (months) }^{1}\end{array}$ & Status & Location/Breeds & Location $^{2}$ \\
\hline $2017-557$ & $\bar{F}$ & 24 & stall - captive & Réserve de la Haute Touche & $\mathrm{MNHN}$ \\
\hline $\mathrm{H} 285$ & M & 24 & stall - captive & Réserve de la Haute Touche & MNHN \\
\hline $2017-560$ & M & 24 & stall - captive & Réserve de la Haute Touche & MNHN \\
\hline $2017-562$ & M & 24 & stall - captive & Réserve de la Haute Touche & MNHN \\
\hline $2017-555$ & $\mathrm{~F}$ & 24 & stall - captive & Réserve de la Haute Touche & MNHN \\
\hline $2017-556$ & $\mathrm{~F}$ & 24 & stall - captive & Réserve de la Haute Touche & MNHN \\
\hline $2017-569$ & $\mathrm{~F}$ & 24 & stall - captive & Réserve de la Haute Touche & MNHN \\
\hline H319 & $\mathrm{F}$ & 24 & stall - captive & Réserve de la Haute Touche & MNHN \\
\hline $2017-554$ & $\mathrm{~F}$ & 24 & stall - captive & Réserve de la Haute Touche & MNHN \\
\hline $2017-571$ & M & 24 & stall - captive & Réserve de la Haute Touche & MNHN \\
\hline $2017-574$ & M & 24 & stall - captive & Réserve de la Haute Touche & MNHN \\
\hline $2017-575$ & M & 24 & stall - captive & Réserve de la Haute Touche & MNHN \\
\hline $2017-558$ & M & 24 & enclosure - captive & Réserve de la Haute Touche & MNHN \\
\hline
\end{tabular}




$\begin{array}{llcl}2017-559 & \text { F } & 24 & \text { enclosure - captive } \\ 2017-561 & \text { M } & 24 & \text { enclosure - captive } \\ 2017-563 & \text { M } & 24 & \text { enclosure - captive } \\ 2017-564 & \text { M } & 24 & \text { enclosure - captive } \\ 2017-565 & \text { F } & 24 & \text { enclosure - captive } \\ 2017-566 & \text { F } & 24 & \text { enclosure - captive } \\ 2017-567 & \text { F } & 24 & \text { enclosure - captive } \\ 2017-568 & \text { F } & 24 & \text { enclosure - captive } \\ 2017-570 & \text { F } & 24 & \text { enclosure - captive } \\ 2017-572 & \text { M } & 24 & \text { enclosure - captive } \\ 2017-573 & \text { M } & 24 & \text { enclosure - captive } \\ \text { PRA_172 } & \text { F } & 23 & \text { wild-caught } \\ 2017-583 & \text { M } & 20 & \text { wild-caught } \\ 2017-585 & \text { F } & 84 & \text { wild-caught } \\ \text { PRA_188 } & \text { F } & 96 & \text { wild-caught } \\ 2017-577 & \text { M } & 17 & \text { wild-caught } \\ & & & \end{array}$

Réserve de la Haute Touche

Réserve de la Haute Touche

Réserve de la Haute Touche

Réserve de la Haute Touche

Réserve de la Haute Touche

Réserve de la Haute Touche

Réserve de la Haute Touche

Réserve de la Haute Touche

Réserve de la Haute Touche

Réserve de la Haute Touche

Réserve de la Haute Touche

Urciers

Urciers

Urciers

Urciers

Chambord
MNHN

MNHN

MNHN

MNHN

MNHN

MNHN

MNHN

MNHN

MNHN

MNHN

MNHN

MNHN

MNHN

MNHN

MNHN

MNHN 


\begin{tabular}{|c|c|c|c|c|c|}
\hline $2017-579$ & $\mathrm{~F}$ & 18 & wild-caught & Chambord & MNHN \\
\hline $2017-580$ & $\mathrm{~F}$ & 18 & wild-caught & Chambord & MNHN \\
\hline $2017-581$ & $\mathrm{~F}$ & 19 & wild-caught & Chambord & MNHN \\
\hline COMP_2013-1262 & $F$ & $16-18$ & wild-caught & Compiègne & MNHN \\
\hline COMP_2013-1265 & M & 21 & wild-caught & Compiègne & MNHN \\
\hline COMP_2013-1273 & M & $36-60$ & wild-caught & Compiègne & MNHN \\
\hline S_bay_lds_1 & $\mathrm{F}$ & 13 & Landrace & Bayerisches Landschwein (German) & ZNS \\
\hline S_bay_lds_3 & M & 33 & Landrace & Bayerisches Landschwein (German) & ZNS \\
\hline S_hv_br_6 & $\mathrm{F}$ & 22 & Landrace & Hannover-Braunschweig Landschwein (German) & ZNS \\
\hline S_hv_br_9 & $\mathrm{F}$ & 51 & Landrace & Hannover-Braunschweig Landschwein (German) & ZNS \\
\hline S_kr1 & $\mathrm{F}$ & $18-20$ & Landrace & French (Corsican) & ZNS \\
\hline S_kr2 & M & $18-20$ & Landrace & French (Corsican) & ZNS \\
\hline S_pol_2 & $\mathrm{F}$ & $36-60$ & Landrace & Polnisches Landschwein (Polish) & ZNS \\
\hline $1850-435$ & $\mathrm{~F}$ & $16-18$ & Landrace & French & MNHN \\
\hline $1860-43$ & $M$ & $16-18$ & Landrace & French & MNHN \\
\hline DUP_C & $M$ & $16-18$ & Landrace & French & MNHN \\
\hline
\end{tabular}


S_bay_lds_4 M $33 \quad$ Landrace $\quad$ Bayerisches Landschwein (German)

${ }^{1}$ Italicized sexes and ages were estimated based on osteological observations, using respectively the morphology of canine cross section (Mayer \&

Brisbin, 1988) and the mandibular tooth eruption and wear stages in occlusal view (Grant, 1982). ${ }^{2}$ Abbreviations: MNHN = Muséum national d'Histoire naturelle (Paris, France); ZNS = Zentralmagazin Naturwissenschaftlicher Sammlungen (Halle/Saale, Germany).

Grant A. 1982. The use of tooth wear as a guide to the domestic ungulates. In: Wilson B, Grigson C, Payne S, eds. Ageing and Sexing Animal Bones from Archaeological Sites, UK: BAR British Series, 991-108

Mayer JM \& Brisbin IL. 1988. Sex identification of Sus scrofa based on canine morphology. Journal of Mammalogy 69:408-412 


\section{Data S2: Digitisation and definitions of landmarks}

a. Digitisation protocol

All specimens were scanned using a Computed Tomography (CT) scanner with a spatial resolution of between 100 and $500 \mu \mathrm{m}$. The five wild boar from Urciers were scanned as live specimens at the Chirurgie et Imagerie pour la Recherche et l'Enseignement (CIRE) platform of the Institut National de Recherche pour l'Agriculture, l'Alimentation et l'Environnement (INRAE). Other individuals were scanned as dry specimens using a CT scanner close to the collections they were housed in. We segmented the bones using the segmentation tools of the Avizo v8.0 software, and then converted the volumes into a three-dimensional PLY format. 
b. Definitions of cranial (1-70) and mandibular (71-94) homologous landmarks.

\section{Landmark Definition}

$1 \quad$ Most anterior midline point of the nasals

2 Most anterior, dorsal midline point of the premaxillae

3, 4 Most anterior point of the nasal-premaxilla suture

5, 6 Most anterior, lateral point of the upper canine alveolus

7,8 Suture at the meeting point of premaxilla, maxilla and nasal

9, 10 Most anterior point of the infraorbital foramen

11, 12 Most posterior point of the infraorbital foramen

13, 14 Most anterior lateral point of the facial tuberosity

15, 16 Most ventral point of the zygomatic-maxilla suture

17, 18 Most anterior, lateral point of the orbit

19,20 Most dorsal point of the lower lacrimal foramen

21, 22 Most posterior point of the supraorbital foramen

23, $24 \quad$ Most dorsal point of the orbit

25, 26 Most ventral point of supraorbital process of the frontal bone

27, 28 Meeting point of the parietal-frontal suture and temporal line

29, 30 Most anterior, dorsal point of the zygomatic process of the squamosal bone

31, 32 Most posterior point of the zygomatic bone

33, 34 Most dorsal point of the zygomatic process of the squamosal bone

35, 36 Most anterior, lateral point of the nuchal crest

37, 38 Most anterior point of the palatine fissure

39, $40 \quad$ Most posterior point of the palatine fissure

41, 42 Most anterior point of the cheek-tooth row (excluding P1)

43, 44 Most posterior point of the cheek-tooth row 
45 Most posterior point of the posterior nasal spine on the palatine bone

46, $47 \quad$ Most ventral, lateral point of the pterygoid process of the sphenoid

48, 49 Most posterior point of the pterygoid hamulus

50, 51 Meeting point of the pterygoid process with the ridge of the lateral pterygoid plate

52, 53 Meeting point of the pterygoid hamulus with the ridge of the medial pterygoid plate

$54 \quad$ Most posterior point of the vomer in contact with the sphenoid

55, 56 Most ventral, lateral, posterior point of the sphenoid-squamosal suture

57, 58 Most ventral, medial, posterior point of the sphenoid-squamosal suture

59, 60 Most posterior, medial point of the petro-occipital fissure

61, 62 Most lateral point of the occipital condyle

63 Most anterior, ventral midline point of the premaxilla

64 Most posterior midline point of the nuchal crest

65, 66 Most posterior, lateral point of the nuchal crest

67, 68 Most lateral point of the foramen magnum

69 Most posterior, dorsal point of the foramen magnum

70 Most anterior point, ventral of the foramen magnum

71, 72 Most anterior, lateral point of the lower canine alveolus

73, 74 Most anterior point of the cheek-tooth row (excluding P1)

75, 76 Most lateral point at the maximum of curvature between the mandibular ramus and corpus

77, 78 Most lateral point at the maximum of curvature between the coronoid process and the mandibular ramus

79, $80 \quad$ Most dorsal point of the coronoid process

81, 82 Most lateral point of the mandibular condyle

83, 84 Most posterior point of the mandibular condyle 
85, 86 Point at the maximum of curvature of the mandibular angle

87 Most ventral, posterior point of the mandibular symphysis

88 Most ventral, anterior point of the mandibular symphysis

89, 90 Most medial point of the mandibular condyle

91 Most dorsal, posterior point of the mandibular symphysis

92 Most dorsal, anterior point of the mandibular symphysis

93, 94 Most anterior point of the mandibular foramen 
c. Definitions of cranial and mandibular curves

\section{Number of}

Starting landmark Ending landmarkt semilandmarks

\begin{tabular}{|c|c|c|}
\hline 15 & 31 & 3 \\
\hline 16 & 32 & 3 \\
\hline 29 & 33 & 3 \\
\hline 30 & 34 & 3 \\
\hline 27 & 35 & 3 \\
\hline 28 & 36 & 3 \\
\hline 64 & 65 & 3 \\
\hline 64 & 66 & 3 \\
\hline 50 & 57 & 3 \\
\hline 51 & 58 & 3 \\
\hline 52 & 55 & 3 \\
\hline 53 & 56 & 3 \\
\hline 75 & 77 & 3 \\
\hline 76 & 78 & 3 \\
\hline 83 & 85 & 3 \\
\hline 84 & 86 & 3 \\
\hline 85 & 87 & 7 \\
\hline 86 & 87 & 7 \\
\hline 87 & 88 & 33 \\
\hline 91 & 92 & 3 \\
\hline
\end{tabular}


d. Wild boar (Sus scrofa) cranium showing the homologous landmarks (red dots) and semilandmarks (blue dots) used in the study.
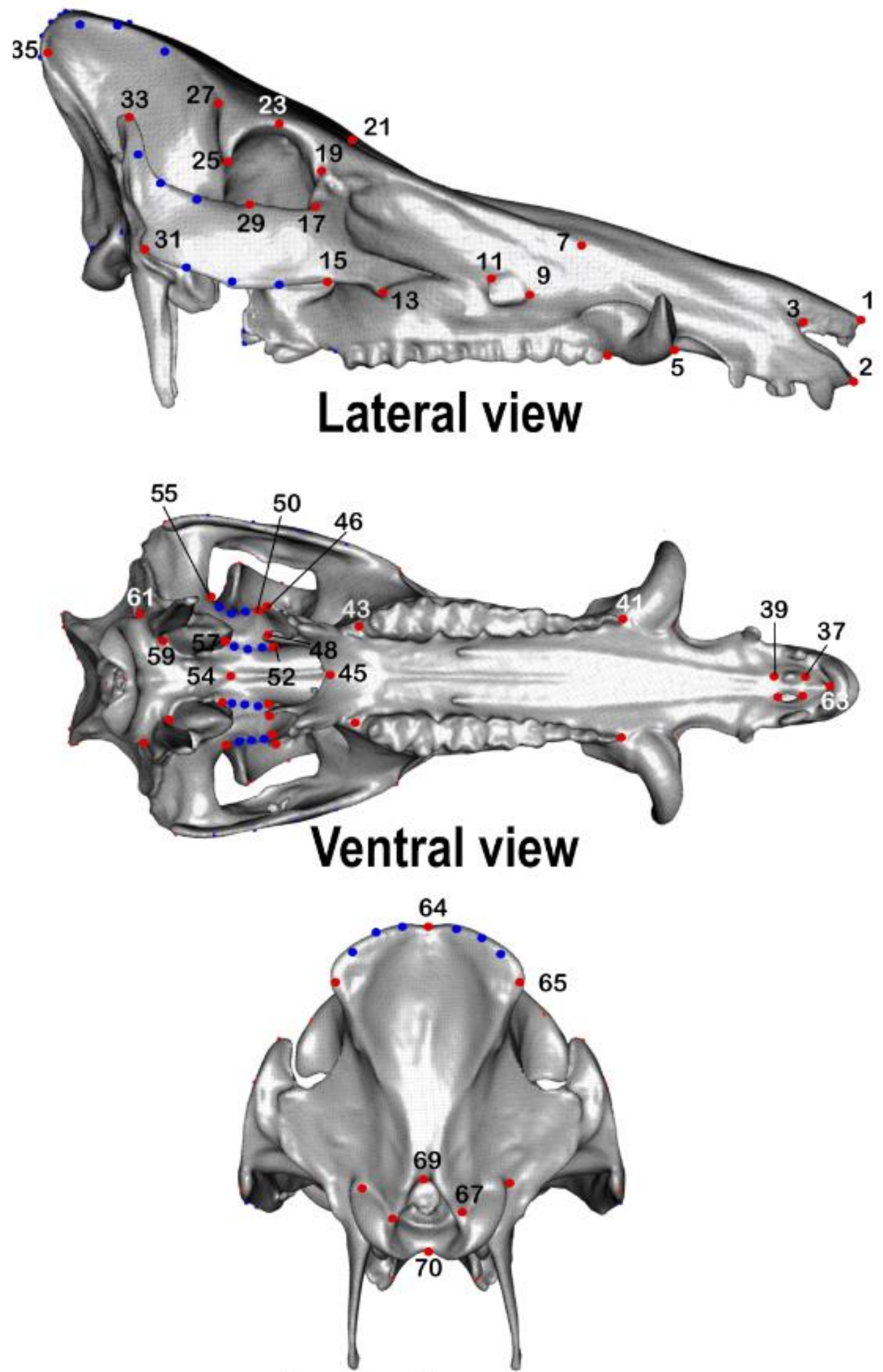

Posterior view 
e. Wild boar (Sus scrofa) mandible showing the homologous landmarks (red dots) and semilandmarks (blue dots) used in the study.

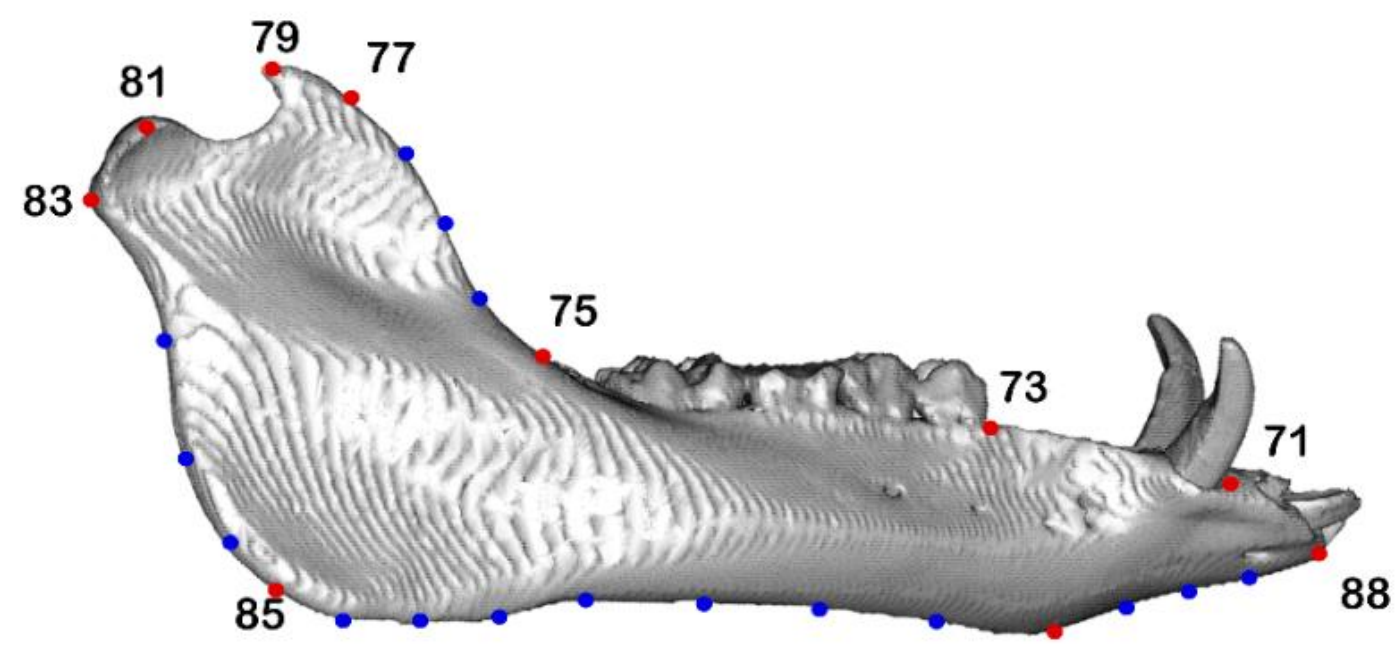

87

\section{Lateral view}

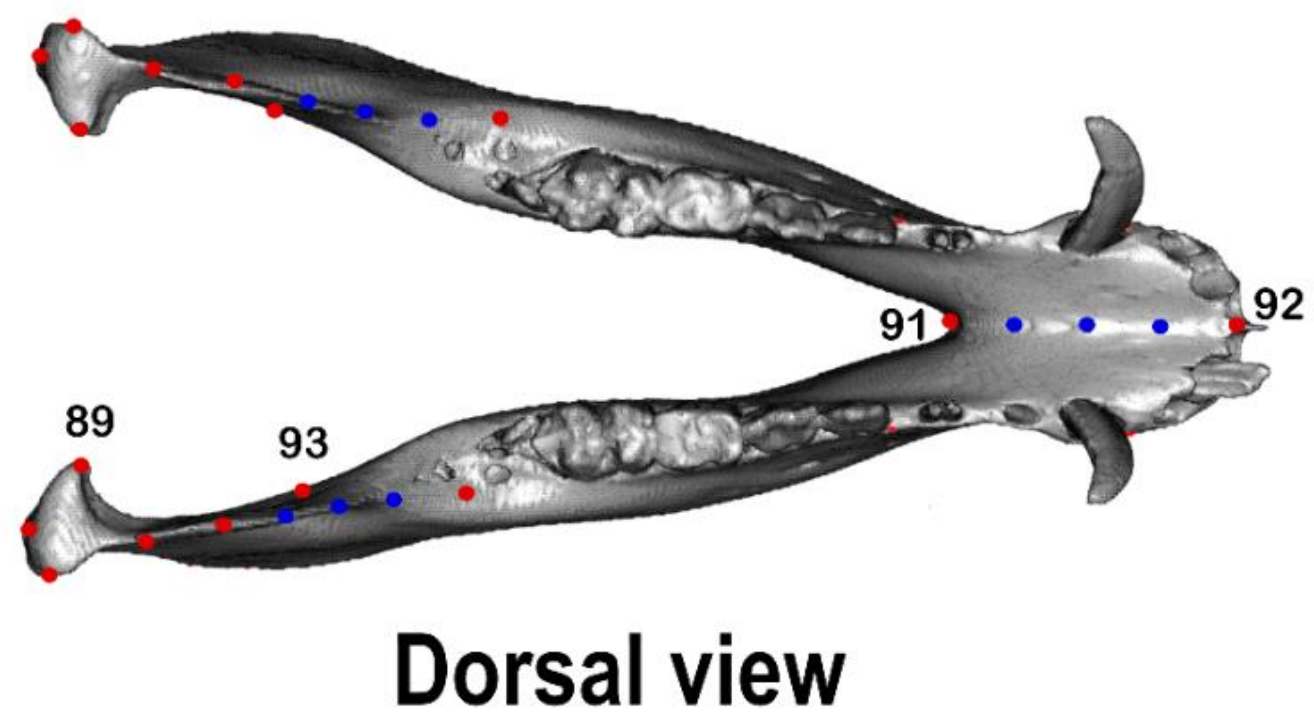




\section{Data S3: Summary of the covariance ratio $(\mathrm{CR})$ test}

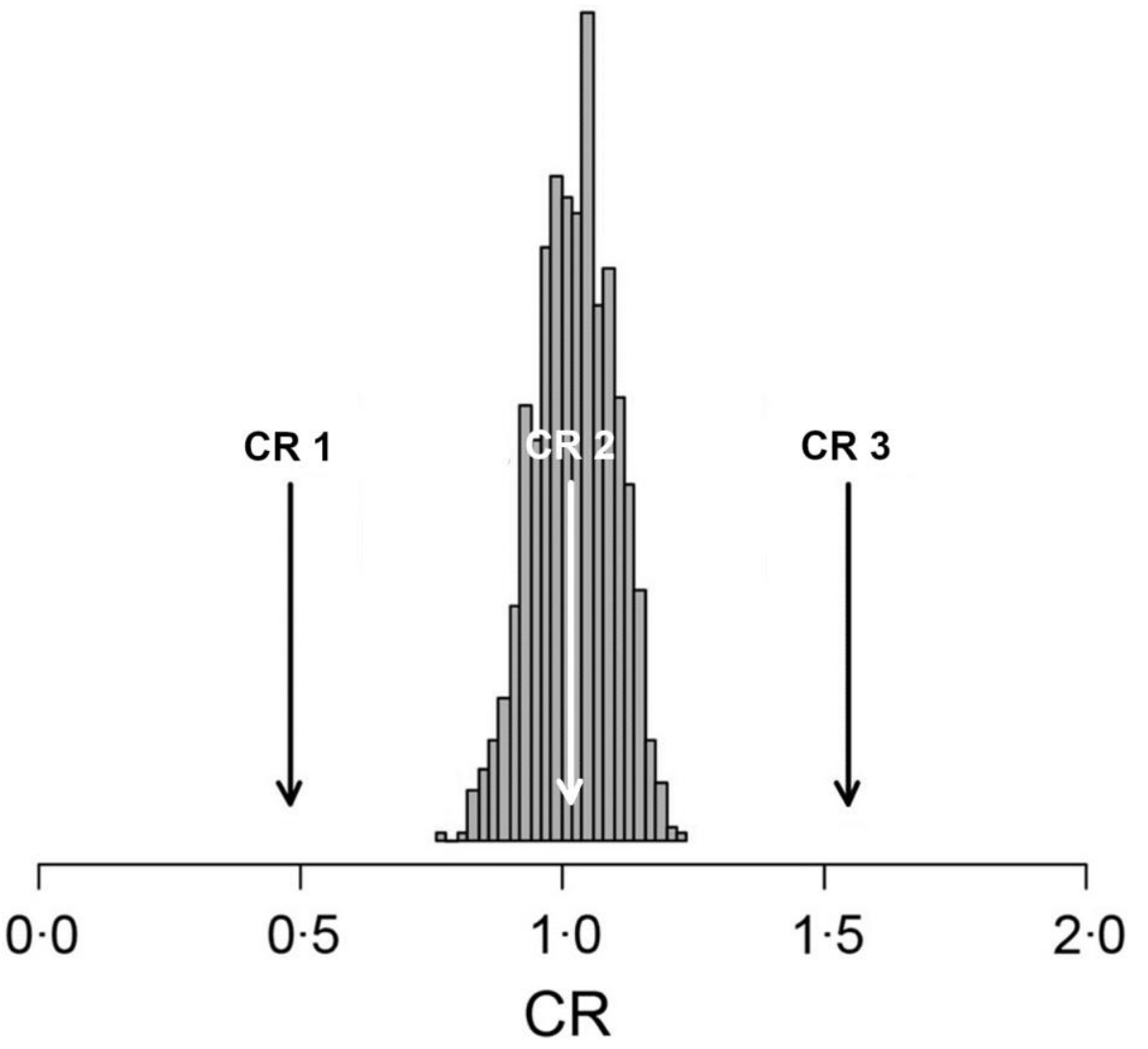

The CR coefficient is compared to a distribution of values obtained by randomly assigning landmarks into subsets. A significant modular signal is found when the observed CR coefficient is small relative to this random distribution. A CR value between zero and one (e.g. CR 1) indicates that the degree of covariation is higher within than between modules, characterising a modular structure. A CR value close to one (e.g. CR 2), within a distribution of values obtained by randomly assigning landmarks into subsets (histogram), describes a structure where the covariations within and between modules are similar, characterising a random set of variables. A CR value larger than one (e.g. CR 3) defines a greater covariation between than within modules, i.e. an integrated structure. Modified after Adams (2016).

Adams, D.C. 2016. Evaluating modularity in morphometric data: challenges with the RV coefficient and a new test measure. Methods in Ecology and Evolution. 7: 565-572. 


\section{Data S4: Variation analyses}

a. Principal component analyses for (a) the cranium and (b) the mandible in the PC1PC2 shape space. Shape changes are depicted in lateral, inferior and posterior views.

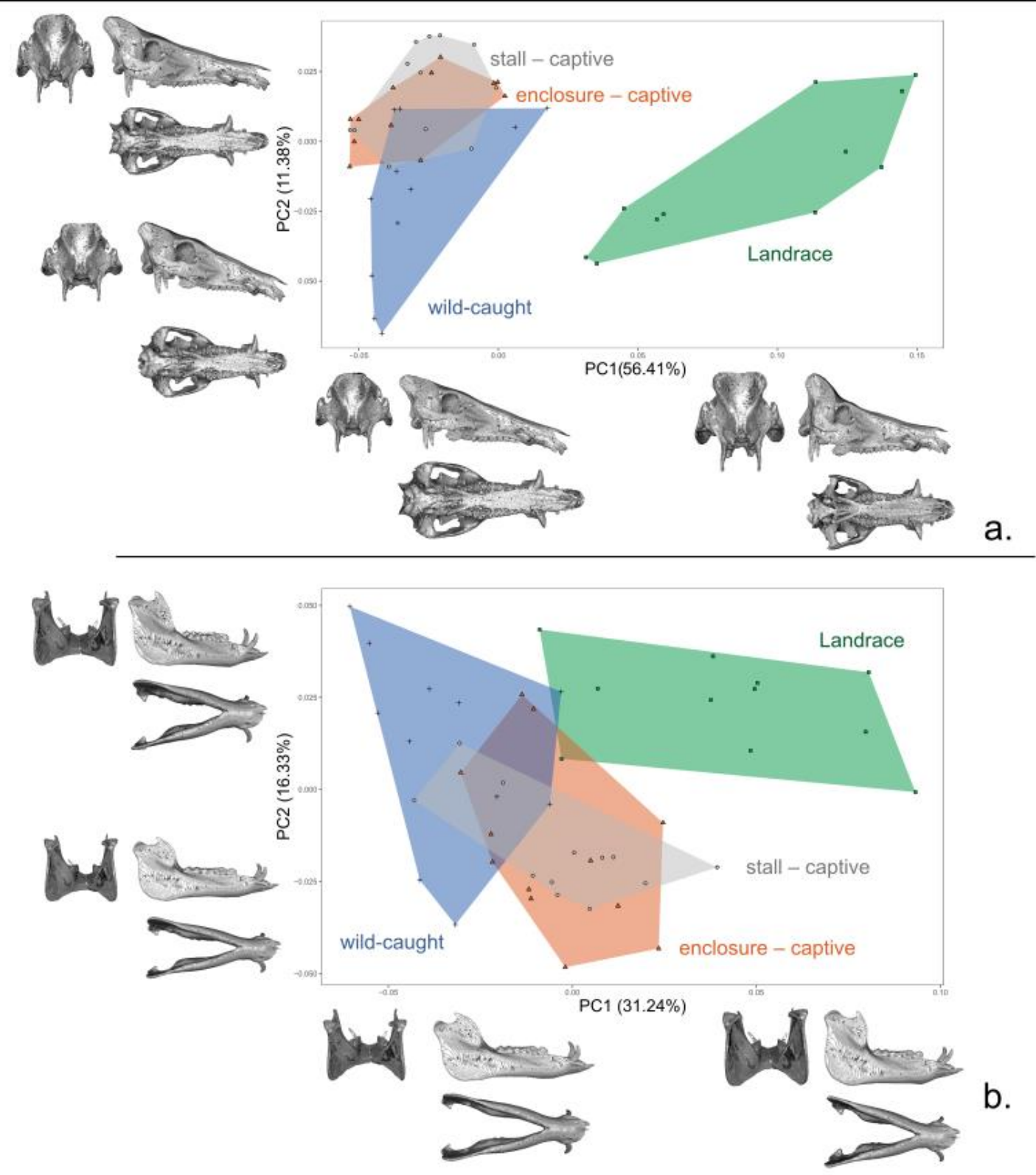

The cranium shape change from wild boar to domestic pig along PC1 is expressed by four main traits: (1) a greater concavity and shortening of the parietal, frontal and nasal regions, (2) a wider zygomatic arch, (3) a more vertical occipital bone, becoming nearly perpendicular to the occlusal plane, and (4) a mediolaterally wider cranium, notably increasing the distance between the two zygomatic processes of the frontal. For the 
mandible, the divergence from wild to domestic animals was characterised by three main traits: (1) a taller and more upright ramus, (2) an anteroposteriorly shorter and taller corpus and (3) a reduced mandibular angle. The cranial shape changes along PC2, from wild-caught to captive wild boar involves three main shifts: (1) an anteroposteriorly longer cranium, (2) more robust zygomatic arches and (3) a more concave cranium. The mandible shape change along PC2 was characterised by (1) a decrease of the corpus length, (2) a taller ramus and (3) a wider mandible in the superior view. 
b. Pairwise ANOVA distance and $p$-values of Procrustes coordinates computed for the cranium and mandible.

\begin{tabular}{|c|c|c|c|c|}
\hline & & 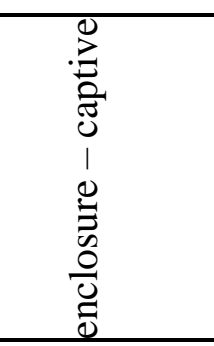 & 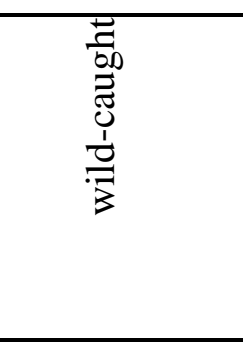 & 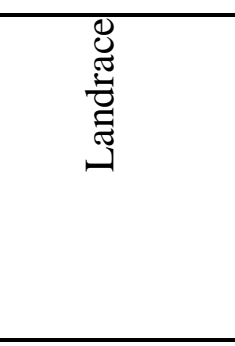 \\
\hline \multicolumn{5}{|c|}{ raw shapes } \\
\hline \multirow[t]{3}{*}{ Cranium } & stall - captive & $0.02(0.91)$ & $0.03(0.26)$ & $0.12(<0.01)$ \\
\hline & enclosure - captive & & $0.04(0.16)$ & $0.11(<0.01)$ \\
\hline & wild-caught & & & $0.11(<0.01)$ \\
\hline \multirow[t]{3}{*}{ Mandible } & stall - captive & $0.02(0.95)$ & $0.05(<0.01)$ & $0.06(<0.01)$ \\
\hline & enclosure - captive & & $0.04(<0.01)$ & $0.06(<0.01)$ \\
\hline & wild-caught & & & $0.08(<0.01)$ \\
\hline \multicolumn{5}{|c|}{ allometry free-shapes } \\
\hline \multirow[t]{3}{*}{ Cranium } & stall - captive & $0.02(0.99)$ & $0.03(0.25)$ & $0.11(<0.01)$ \\
\hline & enclosure - captive & & $0.03(0.28)$ & $0.11(<0.01)$ \\
\hline & wild-caught & & & $0.09(<0.01)$ \\
\hline \multirow[t]{3}{*}{ Mandible } & stall - captive & $0.02(0.89)$ & (0.03) 0.10 & $0.06(<0.01)$ \\
\hline & enclosure - captive & & $0.06(0.04)$ & $0.06(<0.01)$ \\
\hline & wild-caught & & & $0.06(<0.01)$ \\
\hline
\end{tabular}

Significant values $(p<0.05)$ are in bold. 
Table 1. Values of PLS, covariance ratios and coefficients for raw shapes and allometry-free shapes. rPLS: PLS coefficient of the first pair of PLS axes, \%EC: percentage of covariation explained by the first pair of PLS axes, CR: Covariance Ratio.

\begin{tabular}{lccccc}
\hline & rPLS & $p$-value & \%EC & CR & $p$-value \\
\hline raw shapes & & & & & \\
all groups & $\mathbf{0 . 8 9}$ & $<\mathbf{0 . 0 1}$ & $\mathbf{8 5 . 6 5}$ & $\mathbf{0 . 8 1}$ & $<\mathbf{0 . 0 1}$ \\
stall - captive & 0.82 & 0.51 & 59.33 & $\mathbf{0 . 7 1}$ & $<\mathbf{0 . 0 1}$ \\
enclosure - captive & $\mathbf{0 . 8 9}$ & $\mathbf{0 . 0 4}$ & $\mathbf{7 6 . 7 4}$ & $\mathbf{0 . 8 4}$ & $<\mathbf{0 . 0 1}$ \\
wild-caught & $\mathbf{0 . 9 7}$ & $<\mathbf{0 . 0 1}$ & $\mathbf{7 2 . 8 6}$ & $\mathbf{0 . 9 5}$ & $<\mathbf{0 . 0 1}$ \\
Landrace & 0.88 & 0.06 & 69.31 & $\mathbf{0 . 8 1}$ & $<\mathbf{0 . 0 1}$ \\
\hline allometry free-shapes & & & & & $<$ \\
all groups & $\mathbf{0 . 8 8}$ & $<\mathbf{0 . 0 1}$ & $\mathbf{9 2 . 6 7}$ & $\mathbf{0 . 7 0}$ & $<\mathbf{0 . 0 1}$ \\
stall - captive & 0.89 & 0.29 & 56.90 & $\mathbf{0 . 8 8}$ & $<\mathbf{0 . 0 1}$ \\
enclosure - captive & $\mathbf{0 . 8 8}$ & $\mathbf{0 . 0 4}$ & $\mathbf{7 6 . 9 0}$ & $\mathbf{0 . 8 4}$ & $<\mathbf{0 . 0 1}$ \\
wild-caught & $\mathbf{0 . 9 7}$ & $<\mathbf{0 . 0 1}$ & $\mathbf{5 6 . 1 4}$ & $\mathbf{0 . 9 7}$ & $<\mathbf{0 . 0 1}$ \\
Landrace & 0.84 & 0.52 & 32.16 & $\mathbf{0 . 8 8}$ & $<\mathbf{0 . 0 1}$ \\
\hline & & & & & \\
\hline
\end{tabular}

Significant values $(p<0.05)$ are in bold. 